\title{
Compact wooden roofs with smart vapour barrier - Pilot project experiences
}

\author{
Nora Schjøth Bunkholt ${ }^{1, *}$, Lars Gullbrekken ${ }^{1}$, Stig Geving ${ }^{2}$, and Tore Kvande ${ }^{2}$ \\ ${ }^{1}$ SINTEF Community, 7046 Trondheim, Norway \\ ${ }^{2}$ Norwegian University of Science and Technology, Department of Civil and Environmental Engineering, 7491 Trondheim, Norway
}

\begin{abstract}
Compact roofs are normally built without organic materials between the vapour barrier and the roof membrane due to moisture safety risks. However, laboratory measurements indicate that organic materials could be used provided that a smart vapour barrier (SVB) is applied at the warm face of the roof construction. The aim of this study is to investigate the moisture and temperature conditions in three fullscale flat compact wooden roofs with SVB. The roofs are part of two pilot projects located in Longyearbyen, Svalbard and Malvik, Norway. The paper presents the two projects including the premises for construction of the roofs and provides preliminary measurement results. The roofs are instrumented to measure moisture content and temperature in the wooden roof beams. The initial results from Longyearbyen show that the moisture content in the wooden beams is low and indicate that compact wooden roofs with SVB may be a solution with acceptable moisture risk in the arctic climate. The initial results from Malvik show that there might be a risk of mould growth in the roof as the built-in moisture in the wooden beams was up to 24 weight- $\%$. In both projects, the moisture content in the beams in general was higher close to the roof underlay than close to the SVB.
\end{abstract}

\section{Introduction}

Compact wooden roofs may provide reduced roof height, less material use, effective construction processes and positive economic effects compared to conventional compact roofs. However, compact roofs are normally built without organic materials between the vapour barrier and roof membrane due to moisture safety risks. Compact roofs typically require a vapour barrier at the warm face of the construction to prevent vapour diffusion and convective moisture transfer from the interior. Conventional vapour barriers such as polyethylene foils (PE-foils) do not provide drying towards the interior. As a result, compact roofs with organic materials are very vulnerable to built-in moisture or leakages, and therefore rarely chosen.

However, calculations and laboratory measurements [1-5] indicate that compact roofs may be constructed with organic materials provided that a smart vapour barrier (SVB) is used at the warm face of the roof construction. An SVB has the potential to vary its vapour resistance dependent on the surrounding climatic conditions. At low relative humidity $(\mathrm{RH})$ the vapour resistance of the material is high, while it decreases when the RH increases. Hence, during winter when the $\mathrm{RH}$ in indoor air usually is low, the vapour resistance of the barrier will be large. In summer, when the RH in indoor air is high, the vapour resistance will decrease and allow for drying of excess moisture towards the interior. See Fig. 1. This possibility for dry-out towards the interior is of particular interest for constructions with a limited possibility of drying outwards, such as compact roofs, or constructions including moisture sensitive materials, such as wood. The use of SVBs may be a costeffective measure to improve the climatic robustness of compact roof structures and reduce risks related to the use of such roofs. Properly used, SVBs may provide robust moisture protection and a roof less vulnerable to increased rain loads.

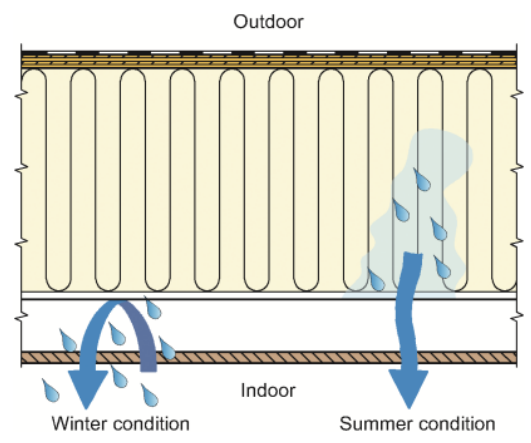

Fig. 1. The functionality of SVBs in summer and winter conditions. (Illustration: SINTEF Community)

The present study aims at demonstrating and documenting the performance of compact wooden roofs with SVB through field testing. The roofs included in the study are part of two pilot projects located in Longyearbyen at Svalbard and Malvik in Norway. Both

\footnotetext{
* Corresponding author: nora.bunkholt@sintef.no
} 
localizations are of interest due to the different climatic conditions.

The main purpose of the study is to give a thorough presentation of the pilot projects, including the given premises for the construction of the roofs. It is of particular interest to investigate how the moisture content (MC) in the load bearing beams of the roofs develops with time, and study deviations in $\mathrm{MC}$ close to the roof underlay and close to the vapour barrier.

\section{Field measurements}

\subsection{Pilot project in Longyearbyen}

The pilot project in Longyearbyen at Svalbard consists of six residential buildings (denoted A-F) with a total of 60 dwellings. See Fig. 2. The buildings were constructed with prefabricated modules during autumn 2018 (buildings A-C) and spring/summer 2019 (buildings E$\mathrm{F})$. Buildings $\mathrm{A}$ and $\mathrm{F}$ are included in the present study.

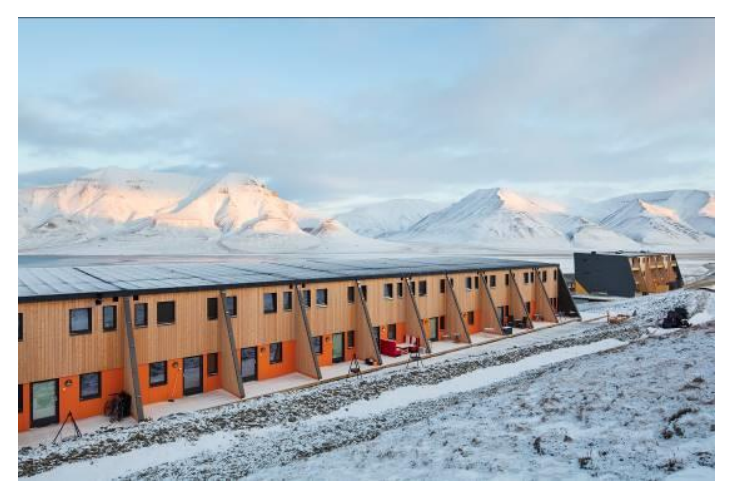

Fig. 2. One of the buildings that are part the pilot project in Longyearbyen. (Photo: Trond A. Isaksen)

\subsubsection{Roof constructions}

The project consists of buildings with flat compact unventilated wooden roofs with SVB. The technical properties of the SVB are presented in [6]. The roofs of building $\mathrm{A}$ and $\mathrm{F}$ are investigated. The roofs are built as part of the prefabricated modules, constructed in a factory building under controlled climatic conditions. They have wooden load bearing beams, mineral wool insulation between the beams, a wooden roof underlay and grey asphalt roofing. See Fig. 4 for details. A roof inclination of $3^{\circ}$ is obtained by inclining the load bearing beams. Key information about the roofs is summarized in Table 1.

The main difference between roof $\mathrm{A}$ and $\operatorname{roof} \mathrm{F}$ is the direction of the load bearing beams. Roof A has load bearing beams normal to the direction of the roof fall, while roof $\mathrm{F}$ has load bearing beams parallel to the direction of the roof fall. See Fig. 4. The installation of beams normal to the roof fall in roof $\mathrm{A}$ will reduce redistribution of moisture due to natural convection in the insulation layer. Therefore, it is of interest to compare measurements of $\mathrm{MC}$ in roof $\mathrm{A}$ and roof $\mathrm{F}$.
Both roofs have an SVB at the warm face of the thermal insulation. However, in the ceiling above bathrooms a conventional PE-foil is mounted above the SVB to limit the risk of moisture transfer from the bathroom air to the roof construction. In roof $\mathrm{A}$, one bathroom is built with an SVB only (without the PE-foil) to investigate whether the SVB has the required functionality above a room with high moisture loads.

\subsubsection{Instrumentation}

The roofs are instrumented with sensors (Hygrotrac S$160-0$, Omnisense) in the wooden loadbearing beams. The registration system consists of base stations with wireless communication to the sensors that are built into the roof construction in different positions. The equipment measures temperature, $\mathrm{RH}$ and $\mathrm{MC}$ in the wooden beams. Measurements have been conducted since the beginning of the construction period and are evaluated as hourly averaged data. All sensors were installed in the wooden beams during the indoor fabrication of the building modules.

\subsubsection{Position of sensors in roof $A$}

In roof A, 26 sensors are positioned in 13 locations in the beams, as shown in Fig 3. In each of the 13 locations, one sensor is installed in top of the beam $(10 \mathrm{~mm}$ from the roof underlay) and one sensor is installed in the bottom of the beam (and $10 \mathrm{~mm}$ from the SVB), as shown in Fig. 4. Sensors are installed in the roof above rooms with different functions (bathroom, bedroom, living room) to investigate possible differences in moisture conditions. In addition, in total five sensors measure temperature and RH in outdoor air (one sensor) and indoor air (four sensors).

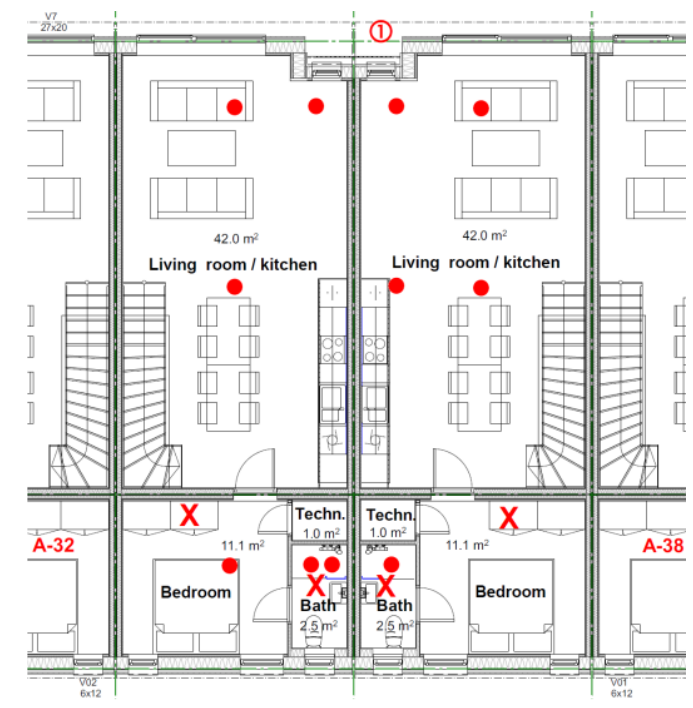

Fig. 3. Instrumentation of roof $A$ in the horizontal plane. "X" shows the position of measurements in indoor air, "(1)" is the position of the sensor in outdoor air, and "๑" indicates the localization of sensors in the wooden beams in the roof. 


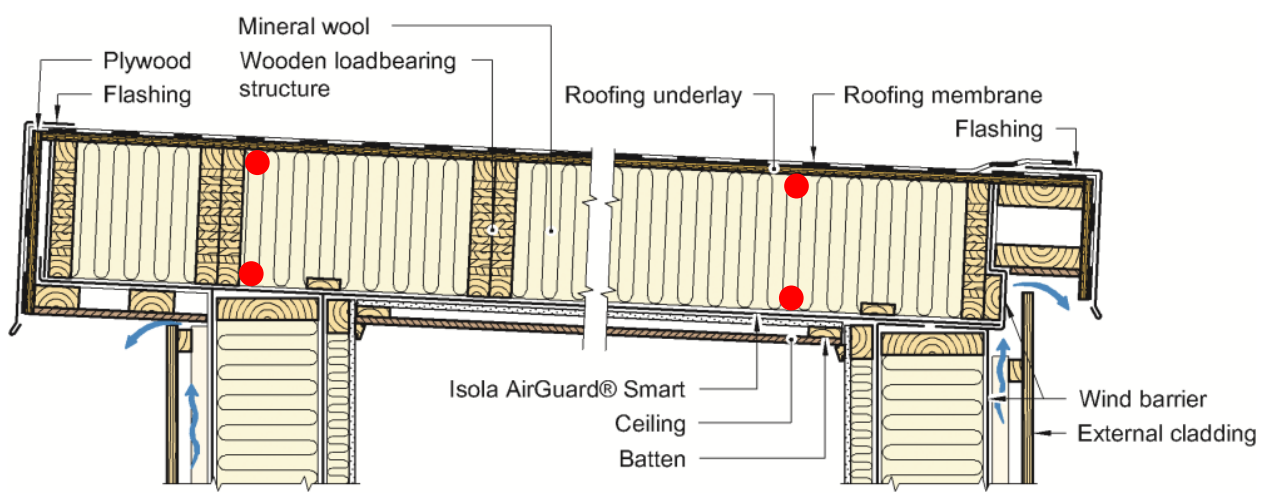

Fig. 4. Roof construction and position of sensors ("•") in roof A (left of figure) and F (right of figure). In each measuring point in the horizontal plane of the roof, two sensors are installed in the cross section. Roof A has loadbearing beams normal to the roof inclination, while roof $\mathrm{F}$ has loadbearing beams parallel to the roof inclination.

\subsubsection{Position of sensors in roof $F$}

In roof F, 24 sensors are installed in 12 locations in the beams, as shown in Fig. 5. As in roof A, two sensors are installed at each of the measuring points - one sensor close to the roof underlay and one sensor close to the SVB. See Fig. 4. Six sensors measure temperature and $\mathrm{RH}$ in outdoor air (one sensor) and indoor air (five sensors).

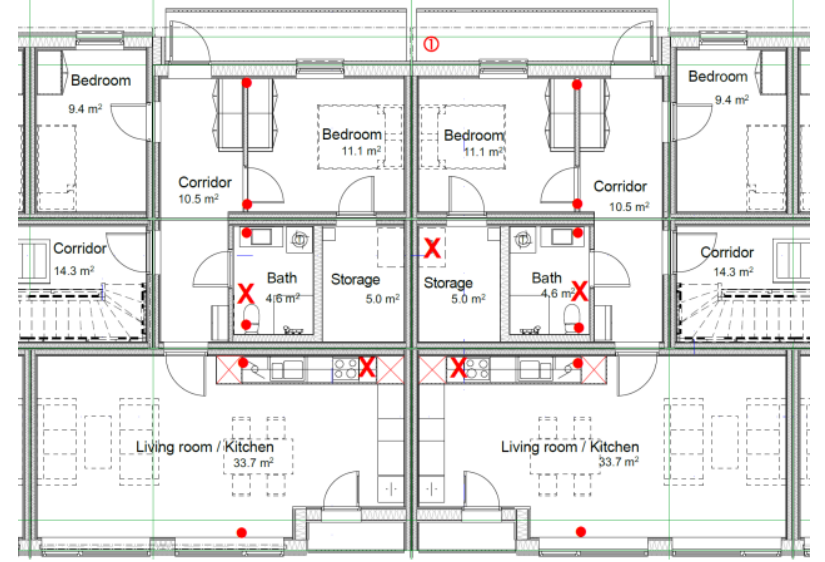

Fig. 5. Instrumentation of roof $F$ in the horizontal plane. " $X "$ shows the position of measurements in indoor air, "(1)" is the position of the sensor in outdoor air, and "॰" indicates the localization of sensors in the wooden beams in the roof.

\subsubsection{Correction of measurements}

The sensors utilised in the study are calibrated for measurements in pine according to TRADA, while the wooden beams in roofs $\mathrm{A}$ and $\mathrm{F}$ are made of spruce. To account for the difference in material, the following correction curve provided by the manufacturer of the sensors is used:

$M C_{\text {spruce }}=-0.504256+\left(1.1386808 \times M C_{\text {pine }}\right)+$ $\left(0.0111586 \times\left(M C_{\text {pine }}-16.5\right)^{2}\right)-\left(0.0010783 \times\left(M C_{\text {pine }}-\right.\right.$ $\left.16.5)^{3}\right)$

where $\mathrm{MC}_{\text {spruce }}$ and $\mathrm{MC}_{\text {pine }}$ are the $\mathrm{MC}$ in weight- $\%$ in spruce and pine, respectively. The deviation between measured and corrected MC-values in the present study is approximately $1.5-2.5$ weight- $\%$ depending on the MC level. The measurements are corrected for temperature internally in the measurement system.

\subsection{Pilot project in Malvik}

The pilot project in Malvik (close to Trondheim) consists of a full-scale residential building, as shown in Fig. 6. The building is denoted D1. It is constructed on-site and is built with a compact wooden roof and SVB.

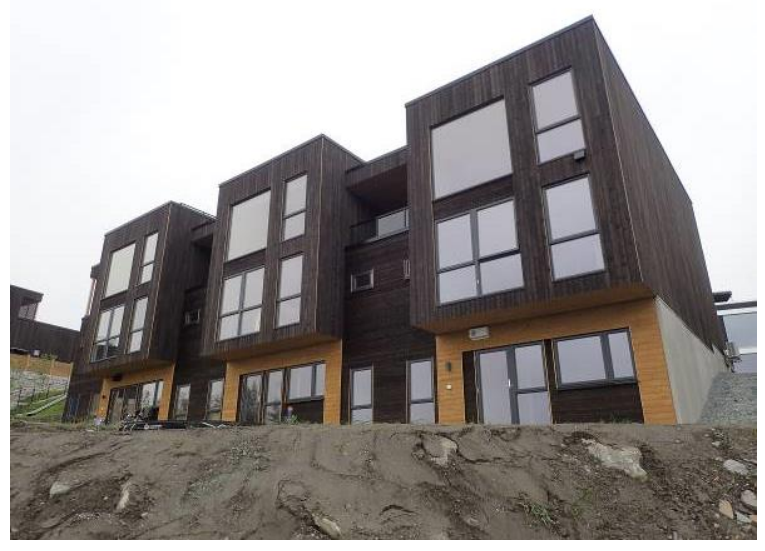

Fig. 6. The building that is part of the pilot project in Malvik. (Photo: Tore Kvande)

\subsubsection{Roof construction}

The roof of building D1 is constructed on-site as a flat compact unventilated wooden roof with SVB at the warm face of the thermal insulation. The technical properties of the SVB are presented in [6]. The roof has wooden I-profile load bearing beams, mineral wool insulation between the beams, a wooden roof underlay and black asphalt roofing, as shown in Fig. 7. Compared to solid wood beams, I-profile beams results in a smaller amount of wood in the roof construction and hence probably less built-in moisture for similar climate during construction. The joists are flat, while tapered insulation on top of the roofing gives a roof slope of 1:40. Information about the roof is summarized in Table 1. 


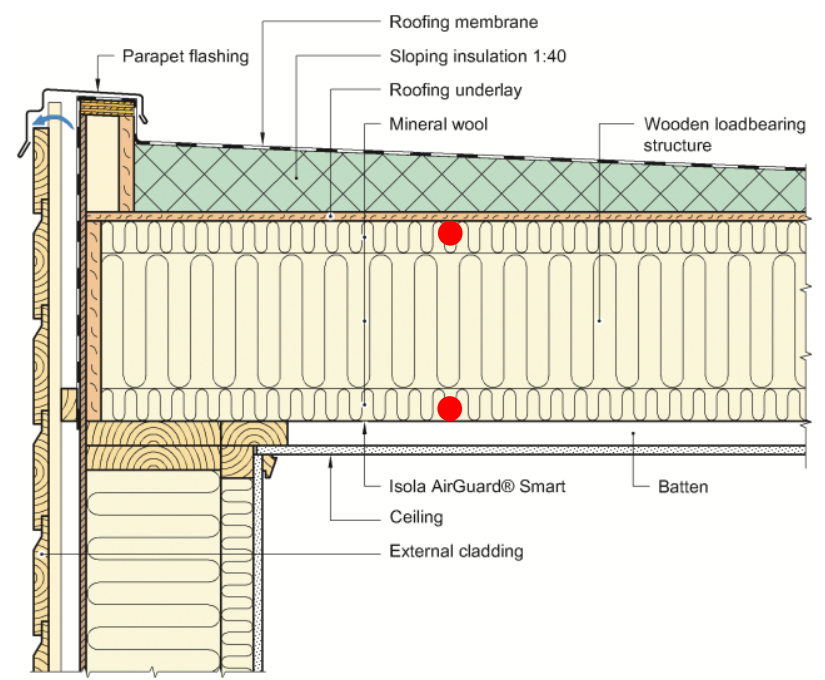

Fig. 7. Roof construction and position of sensors ("•") in the cross section of roof D1. In each measuring point in the horizontal plane of the roof, two sensors are installed in the cross section.

\subsubsection{Instrumentation and position of sensors}

Roof D1 is instrumented with sensors (Omnisense Hygrotrac S-160-0) in the flanges of the wooden Iprofile beams. The sensors and registration system used is equal to those described for roofs A and F. Sensors were installed in the beams 2 weeks after the roof and walls were externally sealed. As for roofs A and F, measurements are evaluated as hourly averaged data. Roof D1 is instrumented with a total of 15 sensors in eight locations, as described in Fig. 8. In each location (except one), sensors are positioned in both the upper and the lower flange of the I-profile beams for measurements close to the roof underlay and close to the SVB, respectively. In one location only one sensor was installed in the upper flange due to a penetration through the lower flange of the beam. The sensors were installed $10 \mathrm{~mm}$ from the roof underlay and $10 \mathrm{~mm}$ from the SVB. The MC electrodes were screwed $22 \mathrm{~mm}$ into the flanges of the beams. Sensors were installed in the roof above rooms with different functions (bathroom, bedroom, living room) to investigate possible differences in moisture conditions.
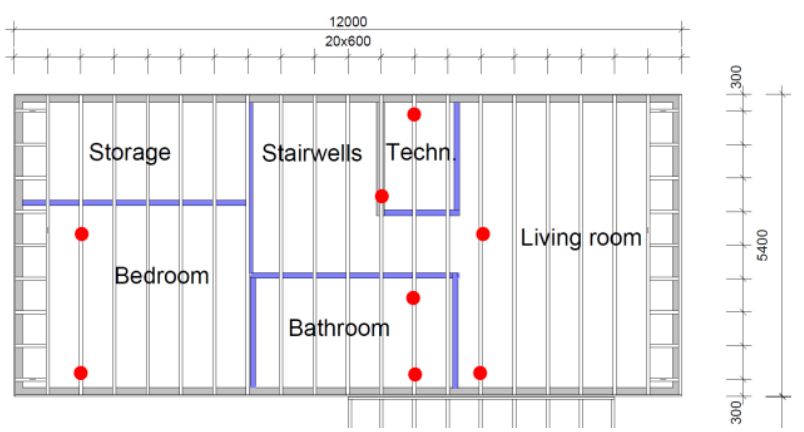

Fig. 8. Instrumentation of roof D1 in the horizontal plane.

\subsubsection{Correction of measurements}

The I-profile beams in roof D1 have flanges of laminated veneer lumber (LVL). Measurement of MC in LVL is expected to differ from measurements on conventional spruce or pine due to the glue layers in the LVL material. The relation between the actual MC in the LVL flanges, $M C_{\mathrm{LVL}}$, of the beams used in the present construction and $\mathrm{MC}$ measured with the sensors, $M C_{\text {pine, }}$ was studied by [7]. Resulting calibration curves describing the relation between $\mathrm{MC}$ measured in LVL and pine is described by Equation (2). The equation was used to correct the measured $\mathrm{MC}$ in the beams. The measurements are corrected for temperature internally in the measurement system.

$$
M C_{\mathrm{LVL}}=0.7295 \cdot M C_{\text {pine }}+2.9989
$$

\subsection{Premises for the use of SVB}

There are multiple important premises to obtain satisfactory functionality when applying SVBs in the three roof constructions. First, the climatic conditions are of great importance for the manner of operation of the SVB. Longyearbyen is situated at $78^{\circ}$ north and has a yearly average precipitation of $213 \mathrm{~mm}$ and a yearly average temperature of $-5.6^{\circ} \mathrm{C}$. June-September is the only period during the year with monthly average temperatures above $0^{\circ} \mathrm{C}$. Consequently, this geographical location results in a relatively low drying capacity during summer when drying towards the interior is possible. Therefore, to take advantage of sunbased heating of the roof, dark roofing directly on the wooden roof underlay is applied on roofs $A$ and $F$ without the use of tapered insulation on top of the roof underlay.

On roof D1 (Malvik) the tapered insulation mounted on top of the roof underlay will decrease heating from the sun on the roof underlay and consequently reduce the drying of the roof construction. Laboratory measurements [2] show, however, that even a shaded roof will dry out eventually, although less heating from the sun will slow down the process. This is assumed to be acceptable as long as the MC in the roof is controlled prior to installation of the thermal insulation and SVB in the roof construction.

The MC in the loadbearing beams has been registered during the construction phase of the two building projects to control the MC at different stages in the process. It was presupposed that the MC should not exceed 15 weight- $\%$ at the time of installation of thermal insulation and SVB in the three roofs (A, F and D1). In addition to the built-in moisture, compact wooden roofs are very vulnerable to air leakages from the interior. Therefore, it is of great importance that the SVB is mounted as a continuous layer. To ensure the continuity of the interior barrier layer, the SVB and thermal insulation were installed prior to the internal walls in all the three roofs.

The moisture resistance of the interior ceiling is of major concern when applying an SVB. The ceiling in roofs with SVB must be vapour open to make it possible 
for moisture that diffuses through the SVB to reach the indoor air. The ceiling in roofs $\mathrm{A}$ and $\mathrm{F}$ consists of gypsum boards and wooden panel. The wooden panel has larger vapour resistance than desired, but perforations in the panels due to installations are assumed to provide sufficient possibility of drying towards the interior. The ceiling in roof D1 consists of gypsum boards with latex paint and is considered sufficiently vapour open. Based on previous measurements [1] the $S_{d}$-value of the combined gypsum board and latex paint is estimated to be approximately $0.13 \mathrm{~m}$.

\subsection{Characteristics of the roofs}

Table 1 describes the characteristics of the three roofs in the two pilot projects. The main differences are the local climate, the construction process, the type of load bearing beams, and the direction of the beams.

Table 1. Comparison of roof A, F and D1

\begin{tabular}{|c|c|c|c|}
\hline Localization & \multicolumn{2}{|c|}{ Longyearbyen } & Malvik \\
\hline Roof & A & $\mathrm{F}$ & D1 \\
\hline Climate & \multicolumn{2}{|c|}{ Arctic } & $\begin{array}{l}\text { Tempered / } \\
\text { continental }\end{array}$ \\
\hline Latitude & \multicolumn{2}{|c|}{$78^{\circ}$ north } & $63^{\circ}$ north \\
\hline $\begin{array}{c}\text { Construction } \\
\text { process }\end{array}$ & \multicolumn{2}{|c|}{$\begin{array}{c}\text { By use of prefabricated } \\
\text { modules }\end{array}$} & On-site \\
\hline $\begin{array}{l}\text { Number of } \\
\text { floors }\end{array}$ & \multicolumn{2}{|l|}{2} & 3 \\
\hline $\begin{array}{c}\text { Wooden } \\
\text { beams }\end{array}$ & \multicolumn{2}{|c|}{$\begin{array}{c}300 \mathrm{~mm} \text { glued laminated } \\
\text { beams }\end{array}$} & $\begin{array}{c}350 \mathrm{~mm} \mathrm{I}- \\
\text { profile beams }\end{array}$ \\
\hline $\begin{array}{l}\text { Direction of } \\
\text { beams in } \\
\text { relation to } \\
\text { roof slope }\end{array}$ & $\begin{array}{l}\text { Normal to roof } \\
\text { slope }\end{array}$ & $\begin{array}{c}\text { Parallel } \\
\text { to roof } \\
\text { slope }\end{array}$ & Not relevant \\
\hline Roof slope & \multicolumn{2}{|l|}{$3^{\circ}$} & $\begin{array}{c}1.4^{\circ} \text { (tapered } \\
\text { insulation) }\end{array}$ \\
\hline $\begin{array}{c}\text { Roof } \\
\text { underlay }\end{array}$ & \multicolumn{2}{|c|}{$18 \mathrm{~mm}$ plywood } & $18 \mathrm{~mm}$ OSB \\
\hline Roofing & \multicolumn{2}{|c|}{ Grey asphalt roofing } & $\begin{array}{c}\text { Black asphalt } \\
\text { roofing }\end{array}$ \\
\hline $\begin{array}{c}\text { Vapour } \\
\text { barrier, } \\
\text { bathrooms } \\
\end{array}$ & $\begin{array}{l}0.15 \mathrm{~mm} \text { PE- } \\
\text { foil, one room } \\
\text { with SVB only }\end{array}$ & $\begin{array}{c}0.15 \\
\mathrm{~mm} \text { PE- } \\
\text { foil }\end{array}$ & $\begin{array}{l}0.15 \mathrm{~mm} \text { PE- } \\
\text { foil }\end{array}$ \\
\hline Downpipe & \multicolumn{2}{|c|}{ None } & Internal \\
\hline
\end{tabular}

\section{Results and discussion}

This section presents preliminary measurements of MC and temperature in roof A (Longyearbyen) and roof D1 (Malvik). As building F (Longyearbyen) was finished during summer 2019, measurements from the roof are not yet presented. Registration of measurements are to be continued in all three roofs in order to control the development in MC over a longer period of time.

\subsection{Roof A - Longyearbyen}

\subsubsection{Variation in $M C$ and temperature}

Measurements from roof A in the period 29.08.201830.08.2019 (one year) are presented in this section. Table 2 shows minimum, maximum and average temperature and $\mathrm{MC}$ in the top and bottom of the wooden beams, investigating registrations from the 26 sensors in roof A. Fig. 9 shows variation in temperature and $\mathrm{MC}$ in one of the measurement positions (two sensors). Important dates in the construction process are specified by vertical black lines. Results from both the sensor in the top of the beam (denoted "top") and bottom of the beam (denoted "bottom") are included. The sensors in the example in Fig. 9 are located in the roof above one of the living rooms in building A. See Fig. 4.

The results show that the temperature in the top of the beams varies much more throughout the year than the temperature in the bottom of the beams. Hence, the risk of condensation and moisture uptake is larger in the upper part of the beams. The temperature is higher close to the roof underlay than close to the SVB in some periods during summer months, as seen in the example in Fig. 9. During these periods dry-out of moisture from the top of the beams through the roof construction and SVB will be possible. However, measurements from roof A show that the MC in both top and bottom of the beams is low throughout the first year of measurements, as given in table 2 . The sensors are not able to measure MC lower than 7 weight- $\%$, which equals 9.4 weight- $\%$ given correction of the measurements using Equation (1). Hence, the actual minimum $\mathrm{MC}$ in roof $\mathrm{A}$ might be even lower. As expected, the MC is larger close to the roof underlay than close to the SVB. The MC measured throughout the first year implies that a compact wooden roof with SVB may have little risk of moisture failure given the arctic climate of Longyearbyen. However, it should be mentioned that the level of built-in moisture was controlled and held very low in this project, thereby the drying-out capacity to the interior was not relevant or tested.

Table 2. Minimum, maximum and average temperatures and $\mathrm{MC}$ measured in roof A

\begin{tabular}{|l|l|l|l|l|}
\hline \multicolumn{2}{|l|}{} & Min. & Max. & Avg. \\
\hline Temperature, top & \multirow{2}{*}{$\mathrm{C}$} & -25 & 36 & 5 \\
\hline Temperature, bottom & & 1 & 27 & 17 \\
\hline MC, top & \multirow{2}{*}{ weight-\%] } & 9.4 & 12.5 & 10.3 \\
\cline { 3 - 5 } & & 9.4 & 12.4 & 9.9 \\
\hline
\end{tabular}

\subsubsection{Comparison of SVB and PE-foil}

Fig. 10 compares the $\mathrm{MC}$ in beams in roof sections above two bathrooms with SVB or conventional vapour barrier (PE-foil), respectively. Results from the sensors in both the top and bottom of the beam are included. The measurements presented in Fig. 10 indicate that the difference in $\mathrm{MC}$ in the roof with smart or conventional vapour barrier is small and that the SVB has the required functionality above a room with high moisture loads. 


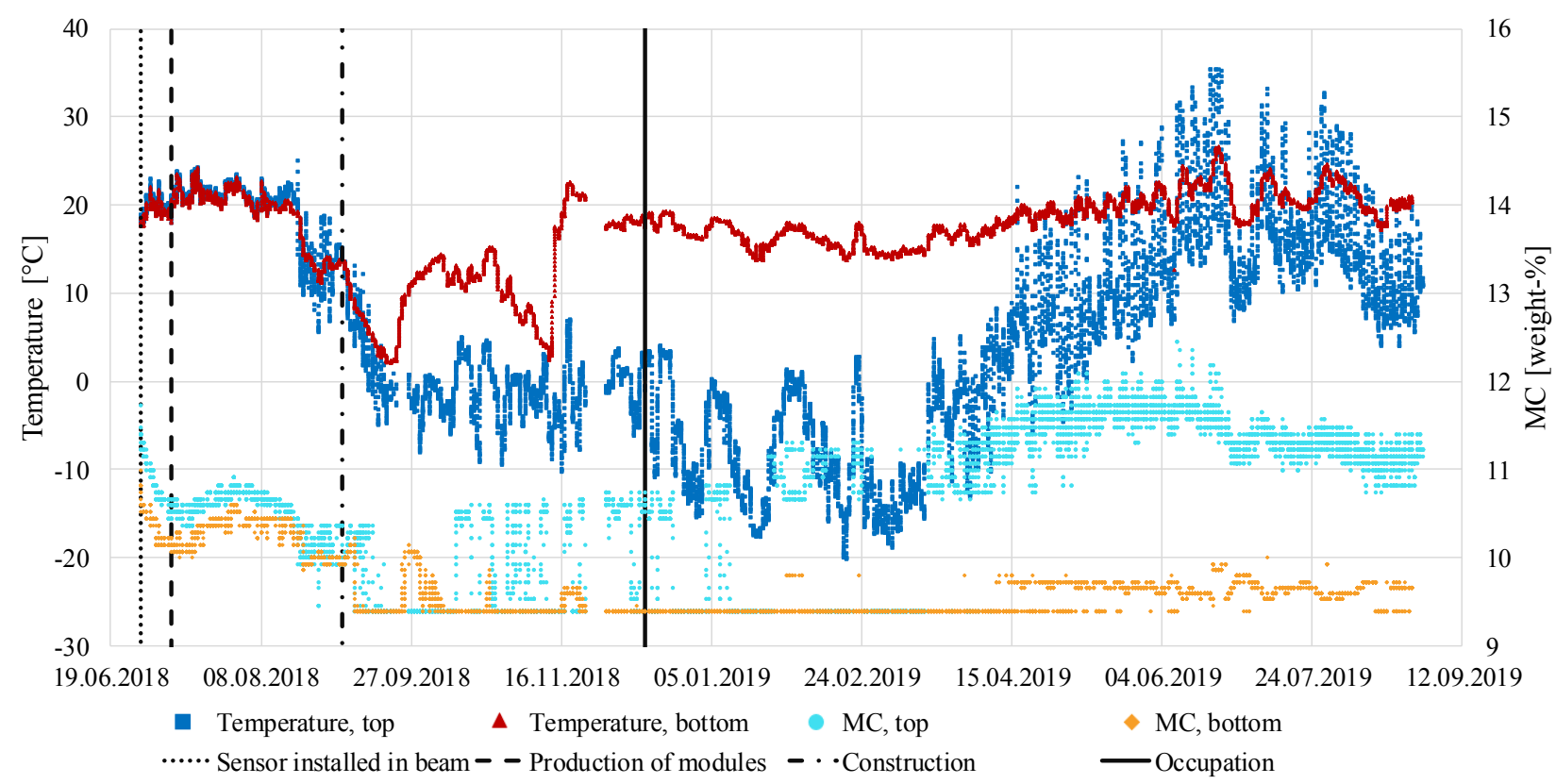

Fig. 9. Variation in temperature and $\mathrm{MC}$ in one of the wooden beams in roof A (Longyearbyen). Measurements are conducted close to the roof underlay ("top") and close to the SVB ("bottom") in the roof above the living room.

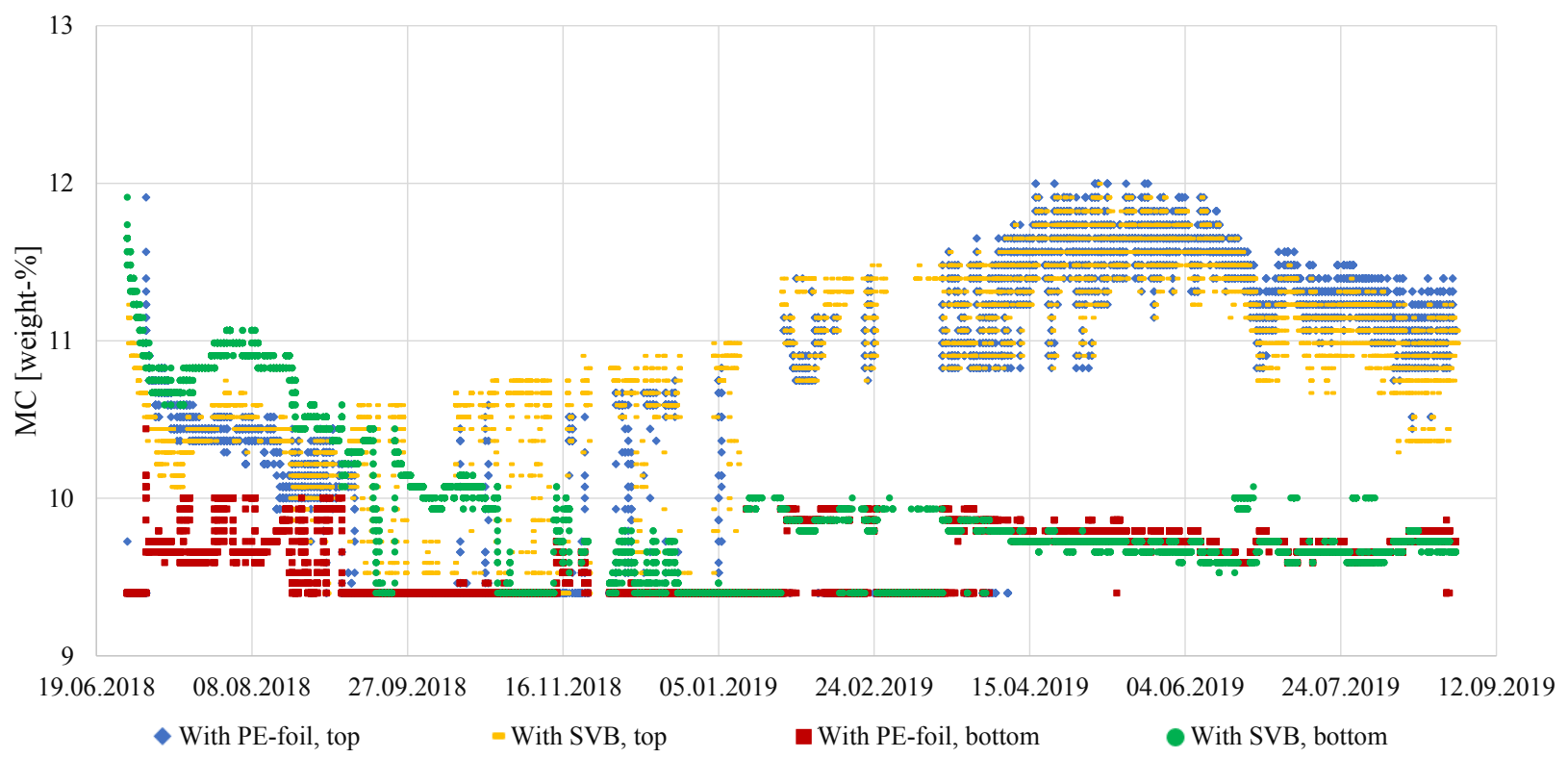

Fig. 10. Comparison of MC in the wooden beams in the roof sections above bathrooms with SVB or conventional vapour barrier (PE-foil) in roof A (Longyearbyen). Measurements in the top and the bottom of the beams are presented.

\subsection{Roof D1 - Malvik}

\subsubsection{Variation in $M C$ and temperature}

This section presents measurements from roof D1 in the period 29.11.2018-05.09.2019 (9 months). Table 3 shows minimum, maximum and average temperatures and $\mathrm{MC}$ levels measured in the top and bottom of the beams, when investigating all the sensors. Fig. 12 shows variation in temperature and $\mathrm{MC}$ in one measurement position (two sensors) in one of the beams in the roof above the living room in building D1 (see Fig. 8).
Important dates in the construction process are specified by vertical black lines. Results from both the sensor in the top of the beam ("top") and bottom of the beam ("bottom") are included. Fig. 11. shows variation in MC for all sensors installed in the top of beams in roof D1.

Table 3. Minimum, maximum and average temperatures and $\mathrm{MC}$ levels measured in roof D1

\begin{tabular}{|l|l|l|l|l|}
\hline \multicolumn{2}{|l|}{} & Min. & Max. & Avg. \\
\hline Temperature, top & \multirow{2}{*}{$\mathrm{C}$} & -10 & 38 & 10 \\
\hline Temperature, bottom & & -10 & 39 & 14 \\
\hline MC, top & \multirow{2}{*}{ weight-\%] } & 9.5 & 29.2 & 18.2 \\
\cline { 3 - 5 } & & 8.3 & 29.6 & 13.3 \\
\hline
\end{tabular}


Studying registrations from all the 14 sensors in the roof, the initial results show that the temperature in general is slightly higher close to the SVB than close to the roof underlay. This is also observed in the example in Fig. 12. As the building was not yet occupied in the period that is investigated, it is expected that the difference in temperature on the warm and cold face of the thermal insulation is small.

The results show that the MC in the wooden beams is high in some periods during the first nine months of measurements. At the date of installation of the SVB (continuous black line in Fig. 12) the MC was measured in the interval $12.1-23.6$ weight- $\%$ in different positions in the roof (including both top and bottom of beams). Seven of the 14 sensors measured MC larger than 15 weight- $\%$ at this date. Nevertheless, the contractor chose to install the SVB due to issues related to the progress in the project. In the period after installation of the SVB (beyond the continuous black line in Fig. 12) the average $\mathrm{MC}$ was 14.6 weight- $\%$. As the built-in moisture (MC at installation of the SVB) was measured up to 23.6 weight $\%$, the results indicate that there might be a risk of mould growth in roof D1.

The higher $\mathrm{MC}$ in roof $\mathrm{D} 1$ may be caused by a combination of the local climate and the construction method that was used. The building was constructed onsite, which increases the built-in moisture compared to using prefabricated modules. This leads to the MC in the roof being higher than the presupposed level of 15 weight $\%$ at the time of installation of the SVB, and the built-in moisture may demand more time to dry out. However, as shown in Fig. 11, the MC in all sensors in top of the beams was below 20 weight- $\%$ at the end of the studied period even though the moisture load on the different beams varied during the period of construction.

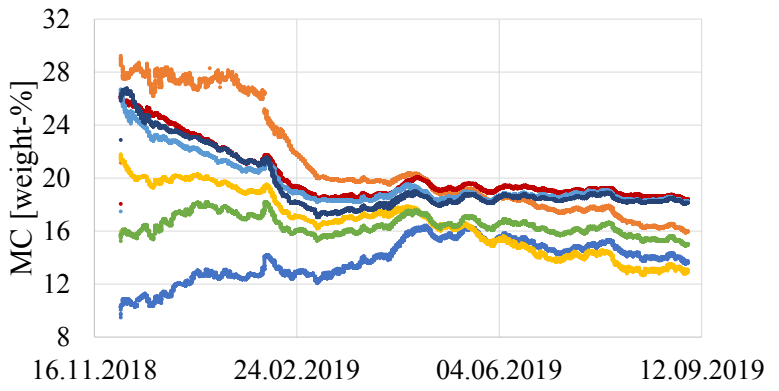

Fig. 11. MC variation in all the sensors installed in top of the beams (close to the roof underlay) in roof D1 (Malvik).

\subsubsection{Relative humidity conditions}

As the MC in roof D1 was large in some measurement positions, the potential risk of mould growth in the roof was investigated. The percentage of measurements with two combinations of temperature (T) and $\mathrm{RH}$ levels in the roof were studied: 1) $\mathrm{T}>5^{\circ} \mathrm{C}, \mathrm{RH}>80 \%$, and 2) $\mathrm{T}>$ $5^{\circ} \mathrm{C}, \mathrm{RH}>90 \%$. The selected temperature and $\mathrm{RH}$ levels are considered conservative regarding mould growth, based on a study by [8] which showed that at a temperature of $5^{\circ} \mathrm{C}$, a $\mathrm{RH}$ of $95 \%$ over four weeks was necessary to initiate mould growth. At a RH of $90 \%$ over four weeks, a temperature of $20^{\circ} \mathrm{C}$ was required to initiate mould growth. When mould growth has first started, the mould can, however, develop further at lower temperatures and $\mathrm{MC}$.

The results are presented in Fig. 13. Sensors 1-7 in the figure are positioned in the bottom of the wooden beams, while sensors $8-14$ are positioned in the top of the wooden beams. The figure shows the percentage of measurements with the given temperature and $\mathrm{RH}$ conditions conducted in the period after the thermal insulation and SVB were installed.

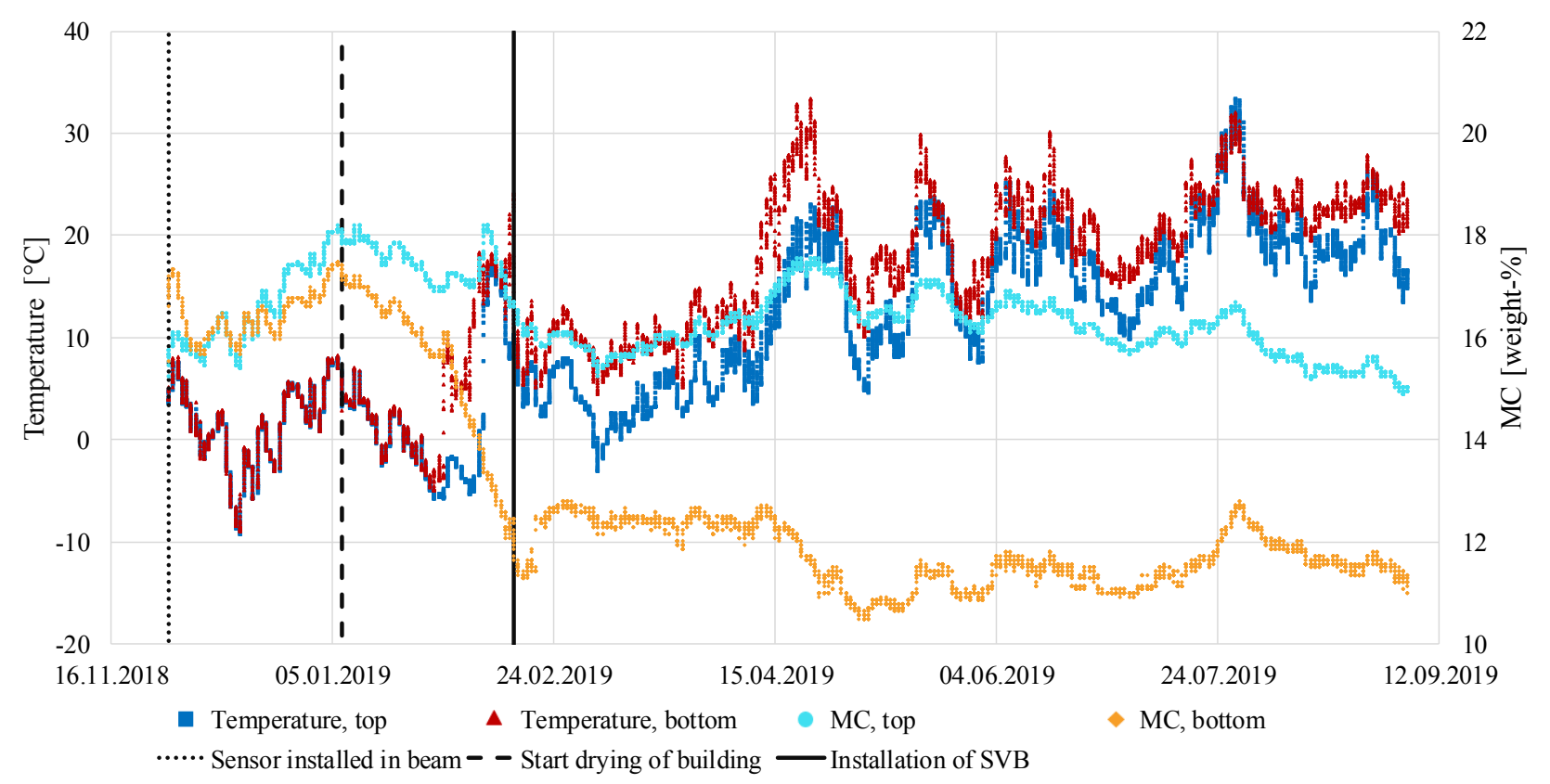

Fig. 12. Variation in temperature and $\mathrm{MC}$ in one of the wooden beams in roof $\mathrm{D} 1$ (Malvik). Measurements are conducted close to the roof underlay ("top") and close to the SVB ("bottom") in the roof above the living room. 
At temperatures above $5^{\circ} \mathrm{C}$, the $\mathrm{RH}$ in the bottom of the beams was lower than $80 \%$ most of the time. This indicates that there is no substantial risk of mould growth in the bottom of the beams, as periods with $\mathrm{RH}$ below $80 \%$ are not considered critical unless mould growth is already initiated. In the top of the beams the RH exceeded $80 \%$ in up to $70 \%$ of the measurements. Hence, there might be a risk of mould growth in the top of the beams. In addition, the temperatures measured in the roof are not large enough to kill mould in the roof. However, the investigations by [8] showed that a RH of $80 \%$ had to be combined with a temperature of $20^{\circ} \mathrm{C}$ over five months to initiate mould growth. The duration of continuous periods with the given temperature and RH levels was not investigated in this study. In addition, the moisture and temperature conditions in the roof underlay, which is a critical point with regards to mould growth, was not investigated. Due to the higher MC levels in roof D1, the roof was opened for inspection 11.07.2019. No mould growth was registered at this time. In addition, two samples cut out of the roof underlay showed dry conditions in the top of the roof.

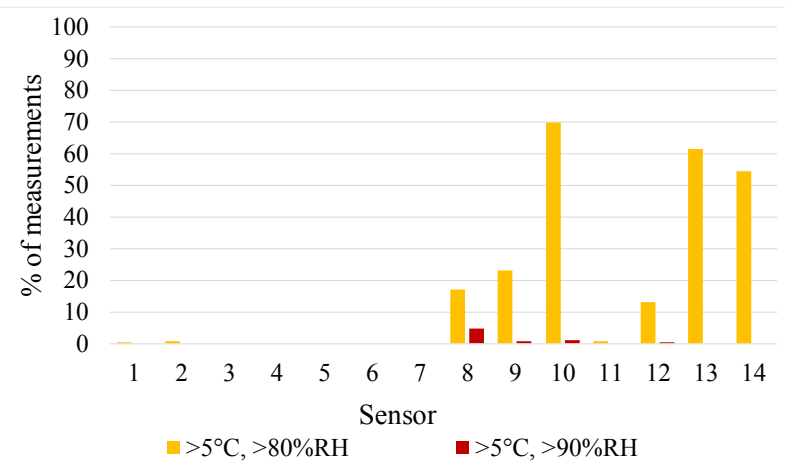

Fig. 13. Percentage of measurements with certain temperature and RH conditions in the roof. Sensors 1-7 and 8-14 are positioned in the lower and upper flange, respectively.

\subsection{Comparison of the two projects}

Preliminary results from both pilot projects show that the temperature and $\mathrm{MC}$ in general is higher close to the roof underlay than close to the SVB. In roof $\mathrm{A}$, all $\mathrm{MC}$ measurements are low, while the $\mathrm{MC}$ in roof $\mathrm{D} 1$ is high in some periods and positions. The main reason for the differences is the different construction methods. The use of prefabricated modules in building A, allows for production in a controlled indoor climate as well as an effective construction process of the building on-site. Building D1 was constructed on-site, which increases the risk of built-in moisture. In addition, the differences in local climate affects how the SVB performs, and hence the moisture gain and dry-out. The risk of mould growth is larger in roof D1 than in roof A. In roof D1, registrations in the top of the beams showed that up to 70 $\%$ of the measurements conducted after the SVB was installed had a $\mathrm{RH}>80 \%$ and temperature above $5^{\circ} \mathrm{C}$. In comparison, this occurred in less than $1 \%$ of the measurements conducted in roof $\mathrm{A}$. The preliminary results from the two pilot projects indicate that wooden roofs with SVB are moisture sensitive. However, precautions to control risks can be taken. Low built-in moisture reduces risk of moisture damages. Given little built-in moisture the results indicate that compact wooden roofs with SVB may be a moisture safe solution.

\section{Conclusion}

The preliminary results from Longyearbyen show that the MC in the wooden beams was low ( $\leq 13$ weight-\%) throughout the first year of measurements. The results indicate that compact wooden roofs with SVB may have acceptable moisture risk in the arctic climate given low built-in moisture. The preliminary results from Malvik show that there might be a risk of mould growth in the roof as the MC was up to 24 weight- $\%$ after installation of the SVB. However, the temperature was in general low in the periods with high MC, which reduces the risk of mould growth. Investigation of longer measurement periods and the functionality of the SVB in cases of higher MC or leakages through the SVB (penetrations) is needed to better conclude on the functionality and risks of compact wooden roofs with SVB. Supplementary simulations should be performed to explore and address limitations and thresholds for applications.

The authors gratefully acknowledge the financial support by the Research Council of Norway and several partners through the Centre of Research-based Innovation "Klima 2050".

\section{References}

1. S. Geving, M. Stellander, S. Uvsløkk. Buildings XII - Thermal Performance of the Exterior Encelopes of Whole Buildings.(2013)

2. S. Geving, E. Thorsrud, S. Uvsløkk. Proc. $2^{\text {nd }}$ Central European Symposium on Building Physics. (2013)

3. S. Geving, E. Thorsrud, S. Uvsløkk. Proc. 10th Nordic Symposium on Building Physics. (2014)

4. S. Geving, T-A. Olsen. 4th Central European symposium on building physics (CESBP 2019). MATEC Web of Conferences 282, 02009 (2019)

5. E.B. Sletfjerding. Smart vapour barriers in compact timber-framed roofs - Parameter analysis and field measurements. Master Thesis. NTNU, Trondheim (2019)

6. SINTEF Certification. Isola AirGuard $\AA$ Smart2 fuktadaptiv dampsperre. Technical Approval. Available at: https://www.sintefcertification.no/Product/Index/27 $\underline{54}$

7. I.M. Birkeland. Moisture in measurements in LVL with wireless sensors [In Norwegian]. Master Thesis. NTNU, Trondheim (2019)

8. H.A. Viitanen. Holzforschung - Int. J of the Bio., Chem., Phy. and Tech. of wood, 51 (1997) 